\title{
Hemorrhagic-Necrotizing Pancreatitis - An Unusual Complication of Mediterranean Spotted Fever
}

\author{
Ivan Baltadzhiev ${ }^{1}$, Nedialka Popivanova ${ }^{1}$, Zaprian Zaprianov ${ }^{2}$ \\ ${ }^{I}$ Department of Infectious Diseases, Parasitology and Tropical Medicine, \\ ${ }^{2}$ Department of Clinical Pathology, Faculty of Medicine, St. George University Hospital, Medical University, \\ Plovdiv, Bulgaria
}

\begin{abstract}
Mediterranean spotted fever (MSF) or Boutonneuse fever is a tick-borne endemic disease caused by Rickettsia conorii. It is characterized by fever, maculo-papular rash and an eschar at the site of tick bite, named black spot or tache noire. MSF has usually mild or moderate course, and has long been considered a benign disease. However, very severe "malignant" forms have been observed with involvement of vital organ systems, serious complications and fatal outcome. Acute pancreatitis is a rare complication of MSF, and hemorrhagicnecrotizing pancreatitis is an unusual consequence of the disease. We report two lethal cases of malignant MSF, presenting with hemorrhagic-necrotizing involvement of the pancreatic gland. An immunofluorescence antibody test confirmed Rickettsia conorii infection. The clinical diagnosis of pancreatitis was defined only in one of the reported patients due to abdominal tenderness and elevated levels of serum amylase. In both cases the diagnosis had histological confirmation at autopsy. Rickettsial vasculitis may play a role in the pathogenesis of pancreatic destruction. This report is an attempt to warn patients and medical staff for this fatal pancreatic involvement in the process of rickettsial inflammation.
\end{abstract}

Keywords: Mediterranean spotted fever, rickettsiosis, Boutonneuse fever, Rickettsia conorii, hemorrhagicnecrotizing pancreatitis

\section{Introduction}

Mediterranean spotted fever (MSF), caused by Rickettsia conorii conorii, strain Malish, is a tick-borne rickettsial infection endemic for the countries along the Mediterranean coast, the Black Sea coast, and Southeast Europe [1]. As a result of globalization and growing tourism, imported cases of MSF are reported in many nonendemic countries and regions. In Bulgaria, R.conorii is transmitted by the dog tick Rhipicephalus sanguineus, and human contact with ticks' intermediate hosts (domestic and stray dogs), is an important determinant in MSF epidemiology. However, depending on location, many other tick species might serve as vectors and/or reservoirs of infection [1]. The main clinical signs and symptoms of MSF are: a skin eschar (tache noire) at the site of tick bite, fever and flu-like manifestations as headache, adynamia, anorexia, myalgia, etc., emerging 3-5 days before appearing of maculopapular rash involving the trunk and extremities, non-sparing the hands and feet. MSF has long been considered a benign disease, however "malignant" forms including severe complications with lethal outcome have been observed $[2,3]$.

In this report we describe two fatal cases of malignant MSF, presenting with a very rare complication hemorrhagic-necrotizing pancreatitis. In both cases the diagnosis had histological confirmation at autopsy. The presence of MSF was confirmed by the indirect immunofluorescent assay. IgG titres of $\geq 128$ and /or IgM titres of $>64$ were considered indicative of acute infection.

\section{Case Reports}

Case report 1: A 67-year-old woman, with preceding history of chronic pyelonephritis, presented with an eight-day history of fever, myalgia, weakness and loss of appetite. A skin rash appeared 4 days after the onset of disease. Additionally, cognitive slowing and generalized seizure developed, necessitating patient's transfer to the hospital intensive care unit (ICU). The medical examination revealed: clouded consciousness, fever $\left(39.5^{\circ} \mathrm{C}\right)$, dehydration and increased muscle tone; abundant diffuse maculopapular and hemorrhagic rash was present over the trunk and extremities, including the palms and feet; tache noire was noted on the left breast; wheezing at the lung bases; muffled heart sounds, pulse rate of 150 beats per minute (bpm) and blood pressure of 115/65 millimeters of mercury $(\mathrm{mmH})$ were registered. The cerebrospinal fluid (CSF) was xanthochromic without other pathological changes. The patient was administered doxycycline - $200 \mathrm{mg} / \mathrm{d}$ through a nasogastric tube. Despite resuscitation efforts the disease developed aggressively: the rash flattened and became bloody; haematemesis and bleeding from the puncture sites appeared; diuresis dropped to anuria; generalized seizures followed. Death occurred $72 \mathrm{~h}$ after admission to the ICU. See the laboratory parameters of the $1^{\text {st }}$ patient on Table 1. 
The autopsy histopathology revealed: Acute hemorrhagic necrosis of the pancreas with local peritonitis in the left hypochondrium (Fig. 1a). Hemorrhagic diathesis: petechial hemorrhages widespread in serous membranes and bleeding in the renal pelvis and lung parenchyma; Cerebral and pulmonary edema.

Table 1 : Laboratory parameters of two patients with malignant form of MSF and hemorrhagic-necrotizing pancreatitis

\begin{tabular}{|c|c|c|c|c|}
\hline $\begin{array}{c}\text { Laboratory } \\
\text { parameters }\end{array}$ & Units (SI system) & $\begin{array}{c}1_{W}^{\text {st }} \text { patient } \\
\text { W }\end{array}$ & $\begin{array}{c}2^{\text {nd }} \text { patient } \\
\text { W }\end{array}$ & Normal levels \\
\hline $\mathrm{Hb}$ & $\mathrm{g} / \mathrm{l}$ & 121 & 117 & $\begin{array}{l}\text { m 140-180 } \\
\text { w } 120-160\end{array}$ \\
\hline Er & $\times 10^{12} / /$ & 3.1 & 4.2 & $\begin{array}{l}\text { m } 4.5-6.0 \\
\text { w } 3.9-5.3\end{array}$ \\
\hline Leuk & $\times 10^{9} / 1$ & 10.8 & 34.3 & $3.5-10.5$ \\
\hline Bands & $\%$ & 31 & 34 & $0.0-6.0$ \\
\hline Segs & $\%$ & 55 & 52 & $42-70$ \\
\hline PLT & $\times 10^{9} / 1$ & 116 & 55 & $140-400$ \\
\hline Fibrinogen & $\mathrm{g} / \mathrm{l}$ & 6.6 & 2.1 & $2-4.5$ \\
\hline PT & $\%$ & 70 & 69 & $70-120$ \\
\hline$\bullet \bullet$ & sec & 28.3 & 25.4 & $14-21$ \\
\hline $\mathbf{A} \square \square \square$ & sec & 37.2 & 32.7 & $27-37$ \\
\hline D-dimer & $\square \mathbf{g} / \mathbf{m l}$ & $(-)$ & $(-)$ & $<0.20$ \\
\hline Total bilirubin & $\square \mathbf{M} / \mathbf{l}$ & 16.2 & 43.3 & $3.4-21$ \\
\hline Direct bilirubin & $\square \mathbf{M} / \mathbf{l}$ & n.a. & 27 & m 0 - 49 \\
\hline ALT & $\mathrm{U} / \mathbf{I}$ & 84 & 84 & w $\quad 0$ - 33 \\
\hline AST & $\mathrm{U} / \mathbf{I}$ & 34 & 34 & 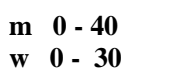 \\
\hline Amylase & U/I & n.a. & 505 & 0 - 96 \\
\hline Total protein & $\mathrm{g} / \mathrm{l}$ & 85 & 62 & $60-83$ \\
\hline Albumin & $\mathrm{g} / \mathrm{l}$ & 31 & 26 & $35-55$ \\
\hline Ure $\square$ & $\mathrm{mM} / \mathbf{l}$ & 54.2 & 50.7 & $\begin{array}{ll}\text { m } & 3.2-8.9 \\
\text { w } & 2.6-7.9\end{array}$ \\
\hline Creatinine & $\mathbf{m M} / \mathbf{l}$ & 878 & 485 & $\begin{array}{l}\text { m } 74-134 \\
\text { w } 44-96\end{array}$ \\
\hline $\mathbf{N a}$ & $\mathrm{mM} / \mathbf{l}$ & 132.8 & 112 & $136-151$ \\
\hline $\mathrm{Ca}$ & $\mathrm{mM} / \mathrm{l}$ & 1.75 & 1.47 & $2.12-2.6$ \\
\hline PH & & 7.27 & 7.28 & $7.35-7.45$ \\
\hline $\mathrm{PO} 2$ & $\mathrm{~mm} / \mathrm{Hg}$ & 51.7 & 36.6 & $83-108$ \\
\hline O2SAT & $\%$ & 82,3 & 63.2 & $94-98$ \\
\hline BE & & -7.7 & -8.4 & \pm 2.3 \\
\hline
\end{tabular}

Legend: $\quad$ w - woman; m - man; n.a. - not available; Hb - Hemoglobin; Er - Erythrocytes; Leuk - Leukocytes; Segs - Segmented Neutrophils; PLT - platelets; PT- prothrombin time; TT- thrombin time; APTT - Activated partial thromboplastin time; D-dimer micrograms per milliliter $(\mu \mathrm{g} / \mathrm{ml})$; ALT - alanine aminotransferase; AST aspartate aminotransferase; Bilirubin micromoles per litre $(\mu \mathrm{M} / 1)$;

Case report 2: A 75-year-old woman, owner of a pet dog, had a seven-day history of fever $\left(40^{\circ} \mathrm{C}\right)$, headache, nausea, and weakness. She had a preceding history of diabetes mellitus and hypertension. On day third of the onset of symptoms a skin rash appeared. She was admitted to the ICU in an impaired general condition: with clouded consciousness, tachycardia and hypotension. An abundant maculopapular rash with cyanotic discoloration and hemorrhagic features was observed on the body and limbs, including palms and feet. There was a tache noire on the left foot. Epigastric tenderness was present on palpation. In the first hours of admission to hospital, she experienced Jacksonian seizures with horizontal nystagmus, and progressed to severe mental obtundation. Generalized convulsions with facial nerve palsy followed, and she progressed into coma. On the first day, the patient was given doxycycline $200 \mathrm{mg} / \mathrm{d}$ by a nasogastric tube and on the second day intravenous ciprofloxacin (ciprinol $200 \mathrm{mg}$ twice daily) was added. Death occurred after 62 hours of resuscitation efforts and mechanical ventilation. See the laboratory parameters of the $2^{\text {nd }}$ patient on Table 1 .

The autopsy histopathology revealed: Acute hemorrhagic-necrotizing pancreatitis with steatonecrosis (Fig. 1b); Generalized necrotizing vasculitis with perivascular lymphohistiocytic infiltration; Multiple petechial hemorrhages on all mucous and serous membranes; Swelling of the brain with wedging of the cerebellar tonsils. 


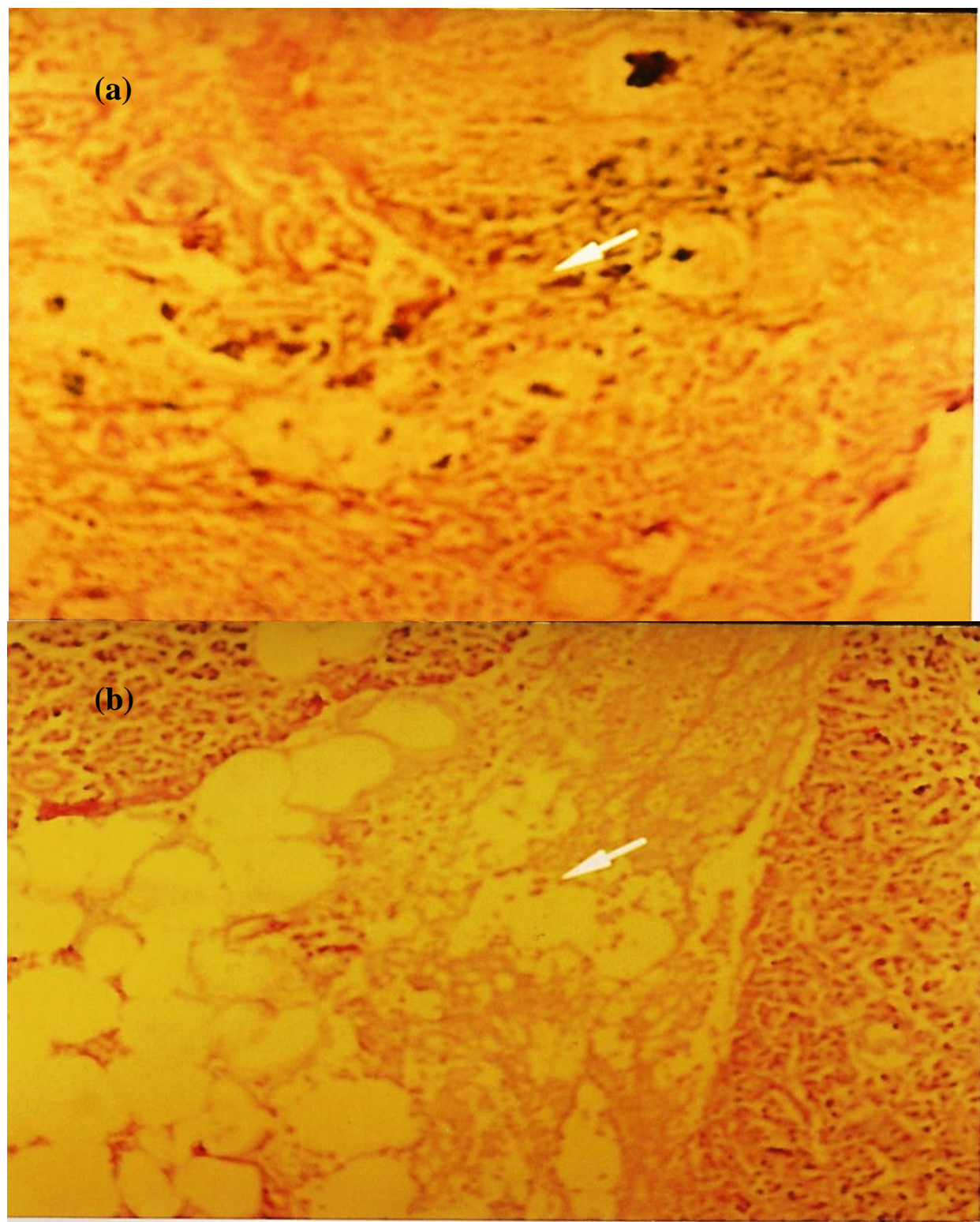

Figure 1 Microscopic view of hemorrhagic-necrotizing pancreatitis (a) and pancreatic steatonecrosis (b), based on paraffin blocks of pancreatic tissue, obtained from patients with a fatal form of Mediterranean spotted fever

(Hematoxylin-Eosin, x 200)

\section{Discussion}

Acute necrotizing pancreatitis is characterized by necrosis in and around the pancreas. It is subdivided anatomically into parenchymal, peripancreatic, and mixed subtypes, and based on clinical progression over time - into early and late clinical phases [4]. The early clinical pancreatitis is associated with a high rate of morbidity and mortality, which is most often due to systemic inflammatory response syndrome (SIRS), associated with systemic organ dysfunction and organ failure [5].

The reported cases of acute hemorrhagic-necrotizing pancreatitis of mixed subtype are not typical for the common forms of MSF. They represent the so-called malignant forms of the disease. The latter are characterized by multi-organ involvement with serious complications and a high mortality rate [6]. Disturbances of the routine laboratory parameters are inherent of malignant MSF forms (Table 1). Acute pancreatitis is diagnosed primarily on the basis of signs, symptoms, and laboratory tests. It is defined clinically as a disorder that includes epigastric in location and radiating to the back abdominal pain, with serum amylase (or lipase) levels more than three times the normal [5]. If these findings are present, some authors consider that imaging is not necessary to make the diagnosis, because its role is limited during the early phase [5]. In the $2^{\text {nd }}$ case of our report, acute pancreatitis was suspected due to the presence of abdominal tenderness and a very high level of serum amylase. In the $1^{\text {st }}$ case, however, the diagnosis was revealed only at autopsy. 
It is suggested that the involvement of the pancreas in MSF is less frequent compared to the gastrointestinal and liver share, and a few cases have been described in the literature [7]. According to some reports, however, rickettsial vascular injury of the pancreas occurs frequently, although the parenchymal lesions might not be severe enough to qualify as pancreatitis [8]. In some of the cases reported in the literature, the pancreatic involvement was mild, with a prompt response to antibiotic therapy $[9,10]$. Another report, however, announced a serious multiorgan involvement, including the pancreas in patients with South African tick bite fever, and rickettsiae were demonstrated in vascular endothelium of pancreatic septa [11].

The most likely mechanism of rickettsial pancreatitis seems to be the increased vascular permeability caused by endothelial cell damages in the microcirculatory system of the pancreas.

\section{Conclusion}

Awareness of the possibility of necrotizing pancreatitis in MSF patients is essential to professionals in order to maintain a high level of clinical suspicion and thus to secure an appropriate treatment. In this context, the study of the serum amylase and lipase level should enter into the routine set of tests in the severe and malignant forms of MSF. This report is an attempt to warn patients and medical staff for the fatal pancreatic involvement in the process of rickettsial inflammation.

Conflict of Interest: None declared.

\section{Reference}

[1]. Parola P, Paddock CD, Socolovschi C, Labruna MB, Mediannikov O, Kernif T et al. Update on tick-borne rickettsioses around the world: a geographic approach. $\square$ Clin. Microbiol. Rev., 26(4), 2013, 657-702.

[2]. Raoult D, Gallais H, Ottomani A, Resch JP, Tichadou D, De Micco P, et al. [Malignant form of Mediterranean boutonneuse fever. 6 cases]. Presse Med. 12(38), 1983, 2375-8.

[3]. Baltadzhiev I, Popivanova N, Zaprianov Z. Malignant forms of Mediterranean spotted fever: risk factors for fatal outcomes. Braz J Infect Dis. 20(5), 2016, 511-2. doi: 10.1016/j.bjid.2016.06.002.

[4]. Banks PA, Bollen TL, Dervenis C, Gooszen HG, Johnson CD, Sarr MG, et al. Classification of acute pancreatitis 2012: revision of the Atlanta classification and definitions by international consensus. Gut 62(1), 2013, 102-111.

[5]. Shyu JY, Sainani NI, Sahni VA, Chick JF, Chauhan NR, Conwell DL et al. Necrotizing pancreatitis: diagnosis, imaging, and intervention. Radiographics. 34(5), 2014, 1218-39. doi: 10.1148/rg.345130012.

[6]. Baltadzhiev IG, Popivanova NI, Stoilova YM, Kevorkian AK. Mediterranean spotted fever - classification by disease course and criteria for determining the disease severity. Folia Med (Plovdiv), 54(4), 2012, 53-61.

[7]. Rombola F. Mediterranean spotted fever presenting as an acute pancreatitis. Acta Gastroenterol Belg. 74(1), 2011, 91-2.

[8]. Randall MB, Walker DH. Rocky Mountain spotted fever: gastrointestinal and pancreatic lesions and rickettsial infection. Arch Pathol Lab Med 108, 1984, 963-7.

[9]. Mansueto S, Di Leo R, Tringali G. Unusual abdominal involvement in rickettsial diseases. JAMA, 249, 1983, 1709-10.

[10]. EL Fane M, Mustapha Sodqi, Sanae Jebbar, Hanane Badi, Latifa Marih, Abdelfattah Chakib et al. Mediterranean Spotted Fever with an Acute Pancreatitis. J Antimicrob Agents. 2, 2016, 129. DOI: 10.4172/2472-1212.1000129

[11]. Walker D.H., Gear J.H. Correlation of the distribution of Rickettsia conorii, microscopic lesions, and clinical features in South African tick bite fever. Am. J. Trop. Med. Hyg.,34, 1985 361-71. 